\title{
La condonación imperfecta de deudas del derecho concursal español ${ }^{1}$
}

\section{The limperfect Second Chance In The Spanish Bankruptcy Law}

Camila Jaramillo Sierra ${ }^{2}$

\section{RESUMEN}

En el presente trabajo se estudia la situación del deudor persona natural en estado de insolvencia, a raíz de la promulgación del Real Decreto Ley 01/2015 en España. Así mismo, se critica la inadecuada reglamentación del mecanismo de la segunda oportunidad del régimen de insolvencia español, a pesar de las recomendaciones y directrices propuestas por organismos internacionales especializados.

Palabras claves: insolvencia, derecho concursal, segunda oportunidad, persona natural, condonación de deudas.

\section{ABSTRACT}

In this paper the author studies the insolvency situation of the individual debtor in Spain, taking into account the Real Decree Act 01/2015. In adition, the author criticises the innadecuate regulation of the fresh start mecanism in

1 Fecha de recepción: 19 de mayo de 2015. Fecha de aceptación: 25 de junio de 2015. Para citar el artículo: Jaramillo, C. "La condonación imperfecta de deudas del derecho concursal español". Revist@ E-Mercatoria, vol. 14, N 1, enero-junio, 2015. DOI: https://doi.org/10.18601/16923960.v14n1.02

2 Abogada, docente e investigadora de la Universidad Externado de Colombia y estudiante de la especialización en Responsabilidad civil y daño resarcible de la misma Universidad. 
the spanish bankrupcy law, nevertheless the recomendations and guidelines draw by international organizations specialized in the subject.

Key words: insolvency, bankruptcy law, discharge, debtor, second chance.

\section{INTRODUCCIÓN}

En el año 2007 la situación financiera mundial, iniciada en Estados Unidos por la crisis de las hipotecas subprime, comenzó a extender sus efectos económicos a Europa.

En España, las reacciones del sistema económico desencadenaron en el año 2008 una crisis en el área inmobiliaria, generando un aumento en el porcentaje del desempleo en las áreas de la construcción y afines, que repercutió en el patrimonio de quienes esperaban incrementar su riqueza, fueren personas jurídicas o naturales.

Aunado al panorama macroeconómico, la crisis interna originada por la disminución de la productividad, la corrupción política y el aumento de la deuda pública implicó el endurecimiento de los préstamos bancarios a familias y pequeños emprendedores, la disminución de los beneficios públicos, la desconfianza en el mercado financiero desde una perspectiva interna e inversionista (generando un mayor desequilibrio por la falta de recursos económicos provenientes del exterior) y causó lo que actualmente se denomina la Gran Recesión o la depresión económica española ${ }^{3}$.

En el año 2012, gracias a los apoyos financieros de la Unión Europea y a las reformas legislativas (reforzamiento de políticas financieras, aumento de impuestos, recorte de la inversión pública, reajuste de salarios, reducción de empleados de entidades estatales etc. ), España comenzó a estabilizar su situación económica, política y social ${ }^{4}$.

Tras la situación descrita, en la que se vieron -y aún se ven- afectadas las entidades financieras, las personas naturales, los pequeños emprendedores, las familias, las personas jurídicas, los inversionistas y el Estado, entre otros, la crisis por insolvencia se expandió causando graves afectaciones en las esferas laboral, económica, social y política.

3 Consecuencia de ello se presenta el mayor caso de suspensión de pagos en la historia del derecho concursal español por parte de la sociedad Martinsa-Fedesa, una de las principales inmobiliarias de Europa, que contaba con un pasivo superior a los cinco mil millones de euros y más de mil trabajadores. Lo anterior como consecuencia del incumplimiento en el pago a los acreedores financieros.

4 ORTEGA, Eloísa y PEÑALOSA, Juan. Algunas reflexiones sobre la economía española tras cinco años de crisis. Banco de España. Documentos Ocasionales N. 1304, 2013. 
Es por lo anterior que, existiendo un régimen de insolvencia especializado para las personas jurídicas como es la ley concursal ${ }^{5}$, el legislador se vio en la necesidad de estructurar un adecuado régimen de insolvencia para la persona natural, que le permitiera superar la crisis económica.

Dicha regulación fue inicialmente propuesta dentro de la ley concursal y luego adicionada por la ley de emprendimiento ${ }^{6}$, sin embargo, las mismas no fueron suficientes y menos aún abordaron de manera particular el tema de la crisis de la persona natural.

Como consecuencia de lo anterior, y siendo una de las leyes más reclamadas por los consumidores en los últimos años de crisis, el presidente Mariano Rajoy, ad portas de un nuevo periodo electoral, y en un afán por legislar sobre la reglamentación concursal del deudor y la inclusión de un mecanismo exonerador de pasivos ${ }^{7-8}$, promulgó el Real Decreto Ley 01/2015, de 27 de febrero ${ }^{9}$.

El presente trabajo investigativo tiene como fin realizar un breve estudio de la situación concursal de la persona natural, la etapa del acuerdo extrajudicial y sobre todo analizar la inclusión del mecanismo de segunda oportunidad, ante lo cual será necesario cuestionarse si la condonación de deudas aquí incluida, adopta las recomendaciones de organismos internacionales especializados, realizadas al derecho concursal español, con el fin de determinar si, la exoneración planteada, brinda soluciones reales a la insolvencia del deudor español.

\section{ANTECEDENTES DEL REAL DECRETO LEY 01/2015}

A modo de introducción, y como se verá a continuación, el régimen concursal de la persona física en España, se ha caracterizado por su retraído ánimo evolutivo. Lo anterior, es consecuencia de la dificultad de independizarlo del concurso empresarial y de su actual ${ }^{10}$ marcada filosofía pro credito-

5 Ley 22/2003, de 9 de julio. BOE núm. 164 de 10 de Julio de 2003.

6 Ley 14/2013, de 27 de septiembre. BOE núm. 233 del 28 de septiembre de 2013.

7 Para los efectos del presente escrito los conceptos exoneración de deudas, segunda oportunidad, perdón, condonación de deudas y discharge tendrán un idéntico significado.

8 BLUM, A. Brian. Bankruptcy and debtor/ creditor, $5^{\mathrm{a}}$ Ed., Estados Unidos, Aspen Publishers, 2010, p. 533. El autor define el descargue de deudas así "The discharge is the statutory forgiveness of the balance of debts that are not paid in full in the bankruptcy case. The debtor's right to receive a discharge as a matter of law, even in the absence of creditor assent, is one of the features that distinguishes bankruptcy from insolvency proceedings under state law (...). Bankruptcy's fresh start is mean to belp the bonest debtor and not to provide a means for the unscrupulous evasion of debt. For this reason, there are provisions in the Code that deny or limit the discharge where the debtor has dealt dishonestly with creditors or bas tried to abuse the spirit and purpose of the Code".

9 Real Decreto Ley 01/2015, de 27 de febrero. BOE núm. 51 del 28 de febrero de 2015.

10 ALFONSO X. Las Siete Partidas. L.III, Tít. XV, Part. V. Resulta necesario traer a colación la presente ley, toda vez que su redacción preponderó por la protección de los intereses del deudor y no de los acreedores, así: "El desamparamiento que faze el debdor de sus bienes (...) ba tal fuerza que después non puede ser el debdor emplazado, nin es tenido de responder en juyzio a aquellos 
ris $^{11}$ que le ha impedido incluir efectivos mecanismos de superación de la insolvencia ${ }^{12}$.

La legislación española fue modificada en el año $2003^{13}$, con el fin de otorgarle a la persona natural la posibilidad de acceder a un proceso concursal no sólo ordinario sino también abreviado. El yerro consistió en aplicar los presupuestos subjetivos de la persona jurídica a la persona natural sin advertir las diferencias jurídicas y patrimoniales de las mismas. Consecuencia de lo anterior, los procesos recuperatorio y liquidatorio concluían de modo opuesto para ambos sujetos. La persona jurídica en el proceso liquidatorio, tras liquidar el haber social extinguía su personalidad jurídica mientras que la persona natural debía liquidar su patrimonio y de no ser satisfechas las acreencias, continuaba siendo deudora.

La mencionada legislación, condenaba a la exclusión social al deudor persona natural que, con o sin culpa, fracasaba, pues reiteraba la obligación que tenía de responder, con sus bienes, de las obligaciones presentes y futuras, según lo emanado por el Código Civil español ${ }^{14}$. Lo anterior, invitaba a las víctimas de la insolvencia, a la economía sumergida y a la suplantación patrimonial para evitar la ejecución del patrimonio personal.

Dicha actitud preventiva del legislador español surge por el temor a que el mecanismo liberatorio sea utilizado para abusar del sistema económico, para evadir el cumplimiento de las obligaciones y para afectar los patrimonios de terceros; prevención que encuentra su origen en el caso americano, donde a raíz del fácil acceso al discharge, se generaron múltiples abusos (incumplimiento de obligaciones con los acreedores; sobreendeudamiento mal intencionado; derroche económico para insolventarse etc.) debiéndose promulgar en el año

a quien deniesse algo: fueras ende si oviesse fecha tan gran ganancia, que podría pagar los debdos todos, o parte dellos, e que fincasse a el de que podiesse vivir." Esta ley previó la liberación del deudor tras la liquidación patrimonial y permitió que, únicamente en el caso en que el deudor no se viera perjudicado, tras su "gran ganancia", debía de pagar las acreencias insolutas.

11 Real Decreto Ley 01 del 27 de febrero de 2015. En la exposición de motivos se menciona al respecto de la inclusión de la condonación de deudas que: "(...) No puede olvidarse con ello que cualquier consideración ética a este respecto debe cobonestarse siempre con la legítima protección que el ordenamiento jurídico debe ofrecer a los derechos del acreedor (...)".

12 GARAGUSO, Horacio Pablo. Fundamentos de Derecho Concursal, Buenos Aires, Editorial Ad-Hoc, 2001. En, SOTOMONTE MUJICA, David Ricardo. Insolvencia transfroteriza: evolución y estado de la materia. Universidad Externado de Colombia, 2009, p. 22. La palabra insolvencia, "derivada de dos vocablos latinos: in - partícula negativa- y solvere - pagar, [...] no pagar."

13 Ob. Cit. Ley 22/2003.

14 CÓDIGO CIVIL ESPAÑOL, artículo 1911: "Del cumplimiento de las obligaciones responde el deudor con todos sus bienes, presentes y futuros". El presente artículo fue derogado por la Ley 22/2003, Ley Concursal. 
2005 el Bankruptcy Abuse Prevention and Consumer Protection Act ${ }^{15}$, limitante del acceso a dicho mecanismo.

Aún si resulta claro que, el legislador español ha actuado de manera reservada, la doctrina ha sido enfática en la necesidad de un régimen de insolvencia que permita al deudor persona natural, recuperarse económicamente tras su fracaso; así lo ha manifestado PULGAR EZQUERRA “(...) Se propugna así la introducción en España de mecanismos, paralelos a los existentes en otros ordenamientos de Derecho Comparado, de exoneración del pasivo insatisfecho (discharge) que promuevan el principio del $<<$ fresh start $>>$ o la $<<$ second chance $>>$ de aquellos deudores de buena fe que por circunstancias sobrevenidas ajenas a su voluntad (enfermedad, separación, paro, elevación de tipos de interés...) no puedan bacer frente a sus obligaciones contraídas, evitándose así que dichos deudores vean truncada su vida por no poder encontrar una solución racional a sus problemas" 16 .

Como consecuencia de la crítica proveniente de la doctrina y la necesidad real de la condonación de deudas, en el año 2013 mediante la reforma de la ley de apoyo a los emprendedores y su internacionalización ${ }^{17}$, el legislador español actuando nuevamente con ligereza, mitigó parcialmente la situación económica de la persona natural. Lo anterior, toda vez que se incluyó el mecanismo de la segunda oportunidad únicamente para el empresario, motivo por el cual las inclusiones que aquí se presentan no resultan del todo relevantes para nuestro estudio, pues los empresarios son tan sólo un porcentaje de las personas naturales.

A pesar de la calificación restringida de la reforma del 2013 y de la tímida actitud del legislador, éste comprobó la necesidad de flexibilizar la legislación concursal por medio de la inclusión de mecanismos liberatorios para el deudor persona natural. Lo anterior en aras de obtener no sólo un beneficio personal, sino general, a escala, pues, permitirle una segunda oportunidad al deudor, conlleva su reingreso al sistema económico y por ende el menor recurso a

15 En la legislación concursal americana, una de las vías concursales para la persona natural es el Chapter 7, el cual se caracteriza por ser un proceso principalmente liquidatorio (liquidation proceeding) en el cual, la persona que desee superar su estado de insolvencia pero que no goza de un abundante patrimonio para solventar sus deudas, deberá entregar a un trustee sus bienes, con el fin de que proceda a su liquidación y distribución, y como consecuencia se aplique el discharge y el fresh start.

Antes de ser publicada Bankruptcy Abuse Prevention and Consumer Protection Act de 2005, el Chapter 7, era la solución más utilizada por los deudores de escasos recursos, sin embrago, a raíz de esta regulación se creó un Test de Discharge que se utilizó a modo de filtro pues se presentaban numerosos casos de abusos de deudores de mala fe.

16 PULGAR EZQUERRA, Juana. Concurso y Consumidores en el marco del Estado Social de Bienestar, en Revista de Derecho Concursal y Paraconcursal, Nº 9, Sección Estudios, Segundo semestre de 2007, La Ley, pág. 43. 
economías sumergidas ${ }^{18} \mathrm{y}$ testaferros que son altamente requeridos con el fin de evitar liquidaciones patrimoniales.

En el mes de febrero, mediante el Real Decreto Ley $1 / 2015^{19}$ se promulgó la ley de mecanismo de segunda oportunidad, reducción de carga financiera y otras medidas de orden social, a continuación procedemos a hacer un estudio de las principales inclusiones que modifican la ley concursal.

Antes de continuar, es menester mencionar que, en contraposición al recatado actuar legislativo, la doctrina española ha velado y vela, aún hoy, por un esquema concursal que facilite el acceso de la persona natural a la negociación de sus deudas, a una recuperación económica y el acceso a un mecanismo de condonación del pasivo que brinde una segunda oportunidad, del mismo modo que ocurre en el derecho comparado europeo ${ }^{20}$, anglosajón, y, actualmente, latinoamericano.

\section{LA INSOLVENCIA DE LA PERSONA NATURAL}

\subsection{ACUerdo EXTRAJUdicial}

Bajo la Ley 14/2013 de apoyo a los emprendedores y su internacionalización, se introdujo la figura del acuerdo extrajudicial de pagos como alternativa al proceso concursal. Esta normatividad fue modificada por el Real Decreto Ley 01/2015 que permitió el acceso de todos los deudores al acuerdo, con el fin de evitar la rigidez que caracteriza al concurso y el colapso judicial, ya que la etapa se agota ante el notario mediante un procedimiento especial.

Para acceder al acuerdo extrajudicial, la persona natural deberá cumplir con unos requisitos mínimos entre los cuales se encuentra el estar en situación de insolvencia o de incumplimiento inminente de sus obligaciones, no haber sido condenado por delitos contra el patrimonio o el orden socioeconómico, y no haberse beneficiado de un acuerdo de refinanciación o extrajudicial dentro de los últimos cinco años ${ }^{21}$.

18 SENENT, Santiago. Discharge y sobreendeudamiento de particulares en el ámbito del derecho norteamericano y español. Documento de Trabajo del Departamento de Derecho Mercantil, número 2012/47, Universidad Complutense de Madrid, 2012, 26. El autor, con la expresión "economía sumergida" se refiere a los medios poco éticos usados por los deudores para afrontar su situación de insolvencia y hallar la recuperación económica que el sistema le niega, lo anterior toda vez que, por medio del uso de su propia identidad se encuentra limitado en la esfera social y crediticia.

19 Ob. Cit. Real Decreto Ley 01/2015.

20 Hasta la expedición del Real Decreto Ley 01/2015, los únicos países europeos que no contemplaban en su legislación concursal un mecanismo liberatorio de deudas eran España, Bulgaria, Chipre y Malta.

21 Ob. Cit. Real Decreto Ley 01/2015, artículo 231. 
El deudor estará en la obligación de aportar un inventario de activos y pasivos juntos con una relación de sus acreedores, la cuantía de los créditos y su vencimiento; información que deberá ser corroborada por el notario quien procederá a comunicar la apertura de las negociaciones al juez competente para la declaración del concurso. Una vez estudiada la información, se citará a los acreedores los cuales no podrán, por el término de dos meses, iniciar ejecuciones contra el patrimonio del deudor (excepto acreedores garantizados con bienes no esenciales), realizar embargos o secuestros etc. Las anteriores limitaciones no aplican para los acreedores de créditos públicos dado su injustificado tratamiento legal, preeminente y especial, motivo por el cual, el deudor deberá adjuntar la solicitud de aplazamiento de pago de los mismos o, su pago efectivo.

Ahora bien, la propuesta de acuerdo de pagos que deberá contener en detalle los recursos previstos para su cumplimiento, podrá incluir quitas, esperas (plazo no superior a diez años) y cesiones de bienes previendo un porcentaje de los ingresos para el pago de los alimentos del deudor y su familia. De ser aceptado por los acreedores, el acuerdo será elevado a escritura pública, se inscribirá en el registro correspondiente y se comunicará al juzgado donde hubiere debido tramitarse el concurso. Si, por el contrario, en el término de dos meses, el notario o el mediador no consideran posible alcanzar un acuerdo, instará al juez del concurso para que inicie el proceso judicial en fase de liquidación.

\subsection{Segunda oportunidad}

Como bien lo establece la ley, es en el marco de esta etapa dónde, tras intentar el cumplimiento total de las obligaciones ${ }^{22}$, se abre campo a la aplicación del mecanismo de la segunda oportunidad, que, como se describe en la exposición de motivos de la ley, tiene como objetivo "(...) permitir lo que tan expresivamente describe su denominación: el que una persona física, a pesar de un fracaso económico empresarial o personal, tenga la posibilidad de encarrilar nuevamente su vida e incluso de arriesgarse a nuevas iniciativas, sin tener que arrastrar indefinidamente una losa de deuda que nunca podrá satisfacer" ${ }^{\prime 23}$.

22 GALGANO, Francesco. Diritto Privato, 7. . ed., Padova, CEDAM, 1992. En HINESTROSA, Fernando. Tratado de las Obligaciones. Concepto, Estructura, Vicisitudes. Universidad Externado de Colombia, 3ra Ed., Bogotá, 2007, 562. "El sistema jurídico le impone al deudor esmerarse lo más posible para sustraerse al riesgo de incumplimiento $y$, por tanto, prodigar el máximo esfuerzo para cumplir (...). El cumplimiento no es solamente un becho útil para el solo acreedor: cuanto mayor sea el porcentaje de obligaciones cumplidas, tanto mayor será el beneficio para todo el sistema económico, ya que cumplir las obligaciones significa incrementar la circulación de la riqueza, aumentar la producción de bienes y servicios, en una palabra, contribuir al desarrollo económico".

Ob. Cit. Real Decreto Ley 01/2015. Exposición de motivos. 
El anterior mecanismo resulta modulador del rigor normativo de los artículos, boy derogados ${ }^{24}, 1911$ del Código Civil, relativo al cumplimiento de las obligaciones con los bienes presente y futuros del deudor, y 1919 y $1920^{25}$ de la misma legislación, que establecen respectivamente que "Si el deudor cumpliere el convenio, quedarán extinguidas sus obligaciones en los términos estipulados en el mismo; pero, si dejare de cumplirlo en todo o en parte, renacerá el derecho de los acreedores por las cantidades que no bubiesen percibido de su crédito primitivo, y podrá cualquiera de ellos pedir la declaración o continuación del concurso", y, "No mediando pacto expreso en contrario entre deudor y acreedores, conservarán éstos su derecho, terminado el curso, para cobrar, de los bienes que el deudor pueda ulteriormente adquirir, la parte de crédito no realizada".

El espíritu de los artículos 1911,1919 y 1920, derogados por la ley concursal, permaneció incólume pues la misma normativa en el artículo 178, apartado $2 \mathrm{do}^{26}$ hizo referencia a que una vez concluido el proceso concursal por liquidación o insuficiencia de masa, la persona natural, permanecía en calidad de deudora de las obligaciones insolutas, motivo por el cual los acreedores gozaban de legitimación en la causa para la iniciación de procesos ejecutivos.

Tal y como puede observarse, el deudor persona natural, bajo la ley concursal se encontraba igualmente desprotegido de un mecanismo que le permitiera soportar dignamente su insolvencia, motivo por el cual, el 27 de febrero de 2015, mediante el Real Decreto Ley 01/2015, la ley concursal fue modificada en lo concerniente a la insolvencia de la persona natural. La normativa mencionada, añadió el nuevo artículo $178 \mathrm{bis}^{27}$, en el que se incluye el beneficio de la exoneración del pasivo insatisfecho una vez concluido el concurso por

24 Los artículos 1911,1919 y 1920 del Código Civil español, fueron derogados por la Ley 22/2003, Ley Concursal, Ley 22 de 2003.

25 MANRESA Y NAVARRO, José María. Comentarios al Código Civil Español. Real Decreto Ley 01 del 27 de febrero de 2015, Exposición de motivos. Afirma MANRESA que "Esta disposición criticada por algunos por dejar en lo incierto los derechos del deudor derivados del convenio, resulta, sin embargo, en extremo justa, si se tienen en cuenta las razones y los motivos, en virtud de los que se autoriza al deudor para celebrar convenios con los acreedores dentro of fuera del juicio del concurso (...) en consideración a las difíciles circunstancias en que se encuentra el que por carecer de bienes bastantes a cubrir su pasivo (...) no puede satisfacer puntualmente todas sus obligaciones $_{i}(\ldots)$ nada extraño tiene (...) que desapareciendo dicha razón por haber cesado las dificultades (...) venga obligado el deudor a satisfacer la parte del crédito no realizada por sus acreedores".

26 Ob. Cit. Ley 22/2003, apartado 2do, artículo 178. "Fuera de los supuestos previstos en el artículo siguiente, en los casos de conclusión del concurso por liquidación o insuficiencia de masa activa, el deudor persona natural quedará responsable del pago de los créditos restantes. Los acreedores podrán iniciar ejecuciones singulares, en tanto no se acuerde la reapertura del concurso o no se declare nuevo concurso. Para tales ejecuciones, la inclusión de su crédito en la lista definitiva de acreedores se equipara a una sentencia de condena en firme".

27 Ob. Cit. Real Decreto Ley/2015. Artículo 178 bis. Beneficio de la exoneración del pasivo insatisfecho 1. El deudor persona natural podrá obtener el beneficio de la exoneración del pasivo insatisfecho en los términos establecidos en este artículo, una vez concluido el concurso por liquidación o por insuficiencia de la masa activa. 
liquidación o por la insuficiencia de la masa activa. La anterior condonación está limitada al actuar de buena fe del deudor, tal y como ha sido recomendado por la Comisión Europea ${ }^{28}$, la CNUDMI ${ }^{29}{ }_{3}{ }^{30}$, el Fondo Monetario Internacional ${ }^{31}$, el Common operational european definition of overindebtedness ${ }^{32} \mathrm{y}$ ha sido incluido en las legislaciones concursales como la americana ${ }^{33}$, francesa ${ }^{34}$, alemana ${ }^{35}$, portuguesa $^{36}$ y colombiana $^{37}$, entre otras.

2. El deudor deberá presentar su solicitud de exoneración del pasivo insatisfecho ante el Juez del concurso dentro del plazo de audiencia que se le bay a conferido de conformidad con lo establecido en el artículo 152.3. 3. Solo se admitirá la solicitud de exoneración de pasivo insatisfecho a los deudores de buena fe. Se entenderá que concurre buena fe en el deudor siempre que se cumplan los siguientes requisitos:

1. - Que el concurso no baya sido declarado culpable.

2. Que el deudor no baya sido ni condenado en sentencia firme por delitos contra el patrimonio, contra el orden socioeconómico, falsedad documental, contra la Hacienda Pública y la Seguridad Social o contra los derechos de los trabajadores en los 10 años anteriores a la declaración de concurso. Si existiera un proceso penal pendiente, el juez del concurso deberá suspender su decisión respecto a la exoneración del pasivo basta que exista sentencia penal firme.

3. ${ }^{\circ}$ Que, reuniendo los requisitos establecidos en el artículo 231, baya celebrado o, al menos, intentado celebrar un acuerdo extrajudicial de pagos (...)."

28 COMISIÓN EUROPEA. Diario Oficial de la Unión Europea, L. 74/65. Recomendación de la Comisión de 12 de marzo de 2014 "Sobre un nuevo enfoque frente a la insolvencia y el fracaso empresarial".

29 En el presente documento, con las siglas CNUDMI, hacemos referencia a la Comisión de las Naciones Unidas para el Derecho Mercantil Internacional.

30 CNUDMI, Guía Legislativa sobre el Régimen de la Insolvencia, Nueva York, 2006.

31 En Informe realizado en el año 2014, el Fondo Monetario Internacional aconseja realizar modificaciones a la legislación española de insolvencia de la persona natural. El documento puede ser consultado en: http://ep00.epimg.net/descargables/2014/07/10/2509f16067f17 898af32a70b8958b979.pdf

32 Common operational european definition of overindebtedness. Contract $\mathrm{n}^{\circ} \mathrm{VC} / 2006 / 0308$, de 19.12.2006. Informe en el que se busca unificar el concepto de sobreendeudamiento y el modo a través del cual se abordará de manera homogénea la insolvencia.

33 United States Code, Bankruptcy Code. Chapter 7, 13.

34 Code de la Consommation, artículo L.330-1: "La situación de sobreendeudamiento de las personas físicas se caracteriza por la imposibilidad manifiesta del deudor de buena fe de bacer frente al conjunto de deudas no profesionales exigibles o por vencer (...)".

35 ARIAS, Javier. Ley de Insolvencia: Insolvenzordnung (InsO). Revista de Derecho Privado, № 1, enero- junio de 1997, Universidad Externado de Colombia, Bogotá, 146. Javier Arias Varona (Trad.). "Artículo $1^{\circ}$.-Objetivo del procedimiento de insolvencia. El procedimiento tiene por objeto la satisfacción general de los acreedores del deudor, mediante la realización del patrimonio del deudor y el reparto del producto resultante, o a través de un arreglo diferente contenido en un plan de insolvencia, especialmente encaminado al mantenimiento de la empresa. Al deudor bonesto se le dará la posibilidad de eximirse de sus obligaciones pendientes".

36 Código da Insolvência e da recuperação de empresas, aprobado por el Decreto Ley no 531, del 18 de marzo de 2004 en el que se introduce el artículo 243 referente al procedimiento de exoneración.

37 Código General del Proceso, Libro III, Sección III, Título IV. 
El mencionado artículo, apoyado por los estudios realizados por la doctrina $^{38}$, sintetiza estas recomendaciones en los siguientes requisitos: 1) Que el concursado no haya sido declarado culpable; 2) Que el deudor no haya sido condenado, en los diez años anteriores, a delitos contra el patrimonio, el orden socioeconómico, falsedad en documento, contra la Hacienda pública, la seguridad social y los derechos de los trabajadores; 3) Que el deudor haya, al menos, intentado un acuerdo extrajudicial con sus acreedores.

Aunado a lo anterior, en el mismo artículo se plantean dos hipótesis para que el deudor insolvente logre el mecanismo de la exoneración del pasivo insatisfecho.

\subsubsection{Primera hipótesis}

La presente opción la hallamos en el numeral $4^{\circ}$ del artículo 178 bis, cuando, sumado a los requisitos de buena fe establecidos por la ley, el legislador impone que el deudor "haya satisfecho en su integridad los créditos contra la masa, y los créditos concursales privilegiados $\mathrm{y}$, si no hubiera intentado un acuerdo extrajudicial de pagos previo, al menos, el 25 por ciento del importe de los créditos concursales ordinarios".

La ley concursal ${ }^{39}$ define los créditos contra la masa como aquellos provenientes de los gastos y las costas del proceso concursal, los gastos de administración concursal, los alimentos del deudor, los gastos generados por la actividad profesional del mismo, los contratos vigentes tras la declaración del concurso y los contratos contraídos durante el procedimiento, entre otros ${ }^{40}$. Y los créditos concursales privilegiados ${ }^{41}$, especiales y generales, como aquellos que, respectivamente, son créditos garantizados (prendarios o hipotecarios) o que afectan a la totalidad del patrimonio del deudor (retenciones tributarias, de seguridad social y demás créditos públicos, créditos por responsabilidad civil extracontractual etc.). Así mismo, la ley define los créditos ordinarios del concurso como aquellos que no son ni privilegiados ni subordinados (in-

38 Ob. Cit. PULGAR EZQUERRA, Juana. Concurso y consumidores en el marco del Estado Social de Bienestar.

39 Ob. Cit. Ley 22/2003, Capítulo III, Sección 1 ra., artículo 84.

40 GURREA CHALÉ, Aurelio. Los créditos contra la masa. La problemática de su pago en el derecho concursal español. En Libro homenaje al profesor Emilio Beltrán, $9^{\circ}$ Congreso Iberoamericano de Derecho Concursal, Instituto Iberoamericano de Derecho Concursal, 2014, p. 147. Respecto a lo anterior, el autor afirma que "Con carácter general, todos los créditos contra la masa tienen en común que se pagarán a sus respectivos vencimientos $y$, por tanto, sin que les afecte el concurso. Este criterio ba sido defendido por la jurisprudencia menor más cualificada, al señalar que los créditos contra la masa <<se pagan de forma autónoma y como si el concurso no existiera pues éste en principio no les afecta $>>$ ".

41 Ibídem, Capítulo III, Sección 3ra., artículos 89, 90, 91. 
tereses, sanciones, créditos a favor de personas especialmente relacionadas, multas etc. $)^{42}$.

Vemos entonces, cómo el deudor en estado de insolvencia, una vez concluido el concurso por liquidación de su patrimonio o insuficiencia de bienes, para hallarse en esta primera hipótesis de acceso a la exoneración o condonación del pasivo, debe cumplir, en su integridad, con las obligaciones contra la masa, concursales privilegiadas (especiales y generales) y con el $25 \%$ de los créditos ordinarios de no haber solicitado el acuerdo extrajudicial, lo cual, trae como consecuencia el cumplimiento de, prácticamente, todas las obligaciones que pueden yacer en cabeza del deudor.

\subsubsection{Segunda hipótesis}

En la segunda hipótesis el deudor tiene la posibilidad de someterse a un plan de pagos para lograr el cumplimiento de las obligaciones ${ }^{43}$; no podrá haberse beneficiado de la exoneración de deudas en los diez años anteriores a la solicitud actual, no podrá haber rechazado ofertas de empleo acordes a sus capacidades, y, debe aceptar de manera expresa el registro de dicha exoneración en el Registro Público Concursal.

En dicha hipótesis la norma establece que la exoneración de deudas se extenderá a la parte insatisfecha de los créditos ordinarios y subordinados con excepción de los créditos públicos y de alimentos.

Las deudas que no queden exoneradas tras la terminación del proceso concursal, deberán ser satisfechas por el deudor dentro de los cinco años siguientes al mismo, a través de un plan de pago propuesto a los acreedores.

A pesar de lo anterior, la ley otorga una potestad judicial de ambigua interpretación al manifestar que el juez podrá, "atendiendo a las circunstancias del caso y previa audiencia de los acreedores, declarar la exoneración definitiva del pasivo insatisfecho del deudor que no bubiese cumplido en su integridad el plan de pagos pero bubiese destinado a su cumplimiento, al menos, la mitad de los ingresos percibidos durante dicho plazo que no tuviesen la consideración de inembargables". Resulta necesario preguntarse si el juez podrá únicamente exonerar las deudas mencionadas como exonerables en la ley o, podrá exonerar al deudor de todo el pasivo insoluto.

42 Ibídem, artículo 92.

43 Ob. Cit. Real Decreto Ley 01/2015. Artículo 178 bis, “(..) 50 Que, alternativamente al número anterior: i) Acepte someterse al plan de pagos previsto en el apartado 6. ii) No baya incumplido las obligaciones de colaboración establecidas en el artículo 42. iii) No baya obtenido este beneficio dentro de los diez últimos años. iv) No baya rechazado dentro de los cuatro años anteriores a la declaración de concurso una oferta de empleo adecuada a su capacidad. v) Acepte de forma expresa, en la solicitud de exoneración de pasivo insatisfecho, que la obtención de este beneficio se hará constar en la sección especial del Registro Público Concursal con posibilidad de acceso público, por un plazo de cinco años". 
De manera general, es menester concluir que, respecto a las hipótesis planteadas anteriormente, no resultan objeto de condonación o exoneración las obligaciones calificadas como créditos contra la masa, créditos privilegiados, especiales o generales y, los créditos públicos.

Lo anterior trae a colación un dilema que, asimismo, vivió la doctrina alemana una vez promulgada la Insolvenzordnung ( $\operatorname{lns} \mathrm{O}$ ), al percatarse de que el deudor que iniciaba el concurso y que buscaba una liberación de las deudas, debía ser un deudor rico ${ }^{44}$, pues los requisitos para salir vencedor en el proceso, implicaban el pago de un porcentaje considerable de las obligaciones, aunado a los altos costes procesales, lo que resultaba contradictorio con el espíritu de la segunda oportunidad.

Si bien el legislador español actuó con bastante retraimiento al elegir los créditos exonerables del pasivo, la estocada final al régimen de insolvencia de la persona natural se encuentra condensada en la posibilidad, otorgada a los acreedores, de que una vez condonadas las deudas insolutas del deudor, puedan revocar dicha exoneración ${ }^{45}$.

A continuación trataremos cada una de las singularidades de la "condonación de deudas" incluida en el Real Decreto Ley 01/2015.

\section{PARTICULARIDADES DE LA SEGUNDA OPORTUNIDAD ESPAÑOLA}

Como pudo observarse, el Real Decreto Ley 01/2015, tuvo intensiones de promulgar una normatividad que favoreciera al deudor persona natural, por medio de la inclusión del mecanismo de la segunda oportunidad, sin embargo, el objetivo de que el deudor no tuviera que "arrastrar indefinidamente una losa de deuda que nunca podrá satisfacer", resultó claramente frustrado toda vez que la condonación de deudas aquí descrita, resulta en su totalidad, incompleta, anacrónica e ineficaz. Lo anterior debido a que aplica sólo para las deudas privadas, no realiza un estudio acucioso de la calificación del concurso, se extiende al cónyuge del concursado y es susceptible de ser revocada.

SCHMIDT, Karsten. El derecho alemán. Una comedia de equivocaciones. Endeudamiento del consumidor e insolvencia familiar. Editorial Aranzadi. España. 2009, 421. Respecto a la inclusión de descargue de deudas, la doctrina afirmaba que "quien solicitaba la liberalización debía bacerlo con los bolsillos llenos porque el primer requisito para su solicitud es que se baya abierto el procedimiento de insolvencia y ello conlleva elevados costes procesales".

45 Cabe mencionar que el Real Decreto Ley 01/2015, no es claro al referirse a las obligaciones del deudor solidario, fiador o avalista pues además de precisar que los mismos no podrán invocar la exoneración del pasivo insatisfecho para no cumplir con sus obligaciones, deja a la libre interpretación del juez la posibilidad de que los mismos acudan al deudor, tras la exoneración, para reclamar la deuda por ellos satisfecha, lo cual restringiría aún más la condonación del pasivo del deudor. 


\subsection{AplicaCión RESTRINGIDA}

La ley de segunda oportunidad al establecer que el deudor para beneficiarse del mecanismo de exoneración deberá haber satisfecho "en su integridad los créditos contra la masa, y los créditos concursales privilegiados" ${ }^{\prime 46}$ restringe los efectos de la condonación de deudas a las acreencias de carácter privado no privilegiadas, es decir a las deudas ordinarias y subsidiarias, dejando de un lado las acreencias públicas.

A pesar de que la preferencia en el pago de las obligaciones al acreedor público ha sido recurrente en las legislaciones concursales, dada la trascendencia que se le da al acreedor Estado, la tutela que con esta legislación se le ha otorgado al crédito público, resulta desmedida pues, desdibuja la finalidad intrínseca del mecanismo liberatorio.

Beneficiar al acreedor público, evitando que se vea perjudicado con la exoneración de pasivos del deudor, implica evitar que el Estado soporte el principal riesgo de una relación obligacional es decir, el no cumplimiento de la prestación ${ }^{47}$. Es por ello que, no resulta razonable el tratamiento privilegiado que en el tema se le otorga al deudor público respecto a los otros acreedores, quienes sí están en la obligación de soportar las consecuencias del concurso.

Ahora bien, haciendo énfasis en el caso en concreto, debe adicionarse que el deudor que acude al proceso de insolvencia tiene comprometido su patrimonio con deudas provenientes, en su gran mayoría, del sistema financiero y del Estado, pasivo que se traduce en créditos privilegiados especiales (pues los créditos financieros están usualmente respaldados por garantías) y en créditos privilegiados generales, clasificación en la que se incluye a los créditos públicos.

Siendo los anteriores créditos de aquellos cuya satisfacción impone la ley, resulta un sinsentido que la segunda oportunidad de la persona natural, no incluya la exoneración de las deudas que ejercen pesos como "losas" en las espaldas de los deudores.

Si el objetivo mismo de la ley es aligerar las cargas económicas a quien se encuentra en incapacidad de cumplir con sus obligaciones, no se justifica obligar al deudor a pagar las deudas que tiene y ofrecerle una condonación sobre las que no es titular o de serlo, representan un porcentaje mínimo de su pasivo.

46 Ob. Cit. Real Decreto Ley 01/2015. Artículo 178 bis, numeral 3,4.

47 BANCO MUNDIAL. Informe sobre el tratamiento de la persona física. Como se señala en el presente informe, excluir el crédito público del concurso de acreedores afecta todo el esquema concursal en la medida en que priva no sólo a los deudores, de dicho beneficio, sino a los acreedores y al sistema económico en general. El Estado, como tal, está en la obligación de tener un tratamiento igualitario respecto al resto de acreedores y de tal modo apoyar el régimen de la insolvencia. El documento puede ser consultado en: http://siteresources. worldbank.org/INTGILD/Resources/WBInsolvencyOfNaturalPersonsReport_01_11_13.pdf 
De lo anterior se concluye que, para que resulte conveniente el mecanismo implementado como segunda oportunidad y genere los efectos económicos esperados, entre las deudas susceptibles de exoneración deben incluirse los créditos privilegiados especiales y los créditos privilegiados públicos pues, de lo contrario, la medida resulta inútil.

\subsection{DesinterÉS EN la CALIFICACIÓN DEL CONCURSO}

La calificación del concurso debe observarse como una de los filtros más relevantes para ingresar al concurso de acreedores y obtener el beneficio del mecanismo de exoneración. Consiste entonces en un estudio que realiza el juez del concurso en aras de identificar las causas que llevaron al sobreendeudamiento del deudor.

El concurso será fortuito cuando el deudor de buena fe se insolvente por causas sobrevenidas de manera imprevista entre las que se hayan una grave enfermedad, un fallecimiento, un divorcio, un despedido etc.

Por su parte, el concurso será calificado culposo ${ }^{48}$ cuando el sobreendeudamiento sea activo, es decir cuando el deudor haya actuado de mala fe y voluntariamente se haya declarado insolvente ${ }^{49}$. Dicho actuar se materializa en la asunción excesiva de deudas, el mal manejo de las finanzas, la dilapidación de bienes, la adicción al consumo etc.

Lo anterior resulta forzoso al momento de estudiar cada caso en concreto pues la buena fe es un requisito sine qua non para acceder al descargue de deudas y evitar que el deudor, resguardándose en la insolvencia, incumpla sus obligaciones. Es por ello que, de no realizarse un análisis en concreto de la situación de cada deudor se podrá otorgar el beneficio a quien no es merecedor y privar al deudor de buena fe, de una salida digna de la crisis.

Respecto a lo planteado, es posible observar cómo el Real Decreto Ley 01/2015, aborda el tema únicamente para considerar que, si el deudor no cometió delitos contra el patrimonio o el orden socioeconómicos entre otros ${ }^{50}$,

Ob. Cit. PULGAR EZQUERRA, Juana. El presupuesto objetivo de la prevención y tratamiento de las crisis económicas de los consumidores. Afirma la autora que "El sobreendeudamiento activo encuentra su causa en la asunción por el consumidor de deudas, de manera incontrolada, sin atención a su nivel de renta y posibilidades de pago (...) el sobreendendamiento pasivo o sobrevenido, cuya causa se sitúa al margen de la voluntad y el comportamiento responsable del consumidor, en conexión con contingencias inesperadas que determinan una incapacidad sobrevenida (...) sobrepasan las previsiones razonables".

49 MILLER, Alejandro. Reflexiones sobre la calificación del concurso y los administradores sociales. En Libro homenaje al profesor Emilio Beltrán, $9^{\circ}$ Congreso Iberoamericano de Derecho Concursal, Instituto Iberoamericano de Derecho Concursal, 2014, p. 36. Haciendo referencia a la definición de concurso culpable, afirma que es "la producción o agravamiento de la insolvencia por conductas dolosas o gravemente culposas".

Ob. Cit. Real Decreto Ley 01/2015. Artículo 178 bis, numeral 2o "Que el deudor no baya sido 
es un deudor de buena fe, que puede presentarse al concurso de acreedores y es merecedor de la exoneración de deudas. La anterior conclusión resulta ligera en la medida en que, además de no cometer delitos, el deudor debió haber actuado de buena fe en los años previos a la solicitud del concurso (cumpliendo con el deber de información al solicitar créditos, no dilapidando ni alzando sus bienes, siendo precavido con sus finanzas etc.).

La presente normativa, no exige un estudio acucioso de la insolvencia de cada deudor, motivo por el cual, nos encontramos ante un sistema concursal de fácil acceso (pues los filtros son sencillos de superar) y de imposible salida victoriosa ${ }^{51}$ para el deudor honesto pero desafortunado ${ }^{52}$.

\subsection{EXTENSIÓN AL CÓNYUGE DEL CONCURSADO}

Aunado a lo anterior, la aplicación de la segunda oportunidad conlleva la extensión de dicho mecanismo al cónyuge del deudor y respecto de las deudas de la sociedad conyugal adquiridas con antelación al concurso ${ }^{53}{ }_{-} 54$.

Cuando en el marco de una sociedad conyugal o comunal, surgen deudas respaldadas por el patrimonio social, ello implica que una vez liquidada la sociedad, tanto los activos como los pasivos serán divididos, por partes iguales, entre los cónyuges. Lo anterior, entonces, justifica la exoneración en la medida en que ésta tenga como alcance únicamente la cuota de la deuda que corresponde cumplir al concursado ${ }^{55}$, mas no justifica que la exoneración de

ni condenado en sentencia firme por delitos contra el patrimonio, contra el orden socioeconómico, falsedad documental, contra la Hacienda Pública y la Seguridad Social o contra los derechos de los trabajadores en los 10 años anteriores a la declaración de concurso. Si existiera un proceso penal pendiente, el juez del concurso deberá suspender su decisión respecto a la exoneración del pasivo basta que exista sentencia penal firme."

51 Nos referimos a una "imposible salida victoriosa" de la crisis pues, como se estudió con antelación, las deudas objeto de la condonación son mínimas y resultan poco trascendentales en el estudio de la insolvencia de la persona natural.

52 Williams v. Estados Unidos Fidelity \& Garantía Co., 236 EE.UU. 549, 236 EE.UU. 554 555.

53 Ob. Cit. Real Decreto Ley 01/2015. Artículo 178 bis, 5, 2. "Si el concursado está casado o en régimen de gananciales y no se bubiere procedido a la liquidación del régimen económico, el beneficio de la exoneración se extenderá al cónyuge del concursado aunque no bubiera sido declarado en concurso respecto de deudas anteriores a la declaración de concurso de las que debiera responder el patrimonio común".

54 La anterior norma tiene su origen en el artículo 77.2 de la Ley Concursal, el cual reza: (...) 2. Si el régimen económico del matrimonio fuese el de sociedad de gananciales o cualquier otro de comunidad de bienes, se incluirán en la masa, además, los bienes gananciales o comunes cuando deban responder de obligaciones del concursado. En este caso, el cónyuge del concursado podrá pedir la disolución de la sociedad o comunidad conyugal y el juez acordará la liquidación o división del patrimonio que se llevará a cabo de forma coordinada con lo que resulte del convenio o de la liquidación del concurso.

55 CUENA CASAS, Matilde. El concurso de acreedores de persona casada en régimen de gananciales. Endeudamiento del consumidor e insolvencia familiar. Editorial Aranzadi. España. 2009, 159. En relación a ello, la autora considera que "En este ámbito la especial 
deudas involucre a su cónyuge y a la totalidad de las deudas respaldadas por el patrimonio social.

Si se analiza lo anterior desde la perspectiva del derecho concursal vemos cómo se incurre en dos yerros; el primero de ellos gira en torno al sujeto del concurso y el segundo respecto al objeto.

El sujeto del concurso es aquella persona, natural o jurídica que se encuentra en estado de insolvencia actual o inminente, y cuyo patrimonio no está en la capacidad de amparar el cumplimiento de la totalidad del pasivo a su cargo.

Ahora bien, con la extensión del mecanismo de exoneración al cónyuge del deudor, se está modificando al sujeto concursal descrito, toda vez que ha sido el deudor, y no su cónyuge, quien desde el principio ha agotado las etapas (entrega de información de pasivos y activos, acuerdo extrajudicial, liquidación o plan de pagos etc.) previas al alcance de la condonación.

No resulta comprensible por qué si el sujeto del concurso de acreedores ha sido el deudor, la ley permite el ingreso de una segunda persona beneficiaria de los efectos de dicho proceso una vez concluido el mismo. Ello desdibuja el mecanismo e implica otorgar sin ningún requisito previo, la condonación de las deudas a un sujeto no concursado.

Lo anterior, además, se aplica desconociendo si el cónyuge se encuentra en estado de insolvencia, en la imposibilidad de cumplir con sus obligaciones, o por el contrario, con la capacidad económica suficiente para su pago.

El segundo yerro se encuentra en el objeto del concurso pues, el mismo, busca regular, a través del proceso concursal, la reorganización (plan de pagos) o liquidación patrimonial del deudor persona natural.

Lo anterior implica que el plan de pagos se hará teniendo en cuenta los activos y pasivos, las calidades especiales del deudor (profesionales, sociales, familiares...) y la liquidación se efectuará únicamente con base en dicho patri-

naturaleza jurídica de la sociedad de gananciales refleja sus consecuencias prácticas. Su consideración como un modelo de comunidad germánica, carente de personalidad jurídica propia, por virtud de la cual los cónyuges carecen durante la vigencia del régimen de cuotas enajenables ( $y$, por ende, embargables), sobre los bienes gananciales impide que en caso de concurso de uno de los cónyuges pueda incluirse en la masa activa la cuota correspondiente a cada cónyuge sobre los bienes comunes, tal y como aconsejaría un escrupuloso respecto al principio de responsabilidad patrimonial universal (art. 1911 CC)".

En el mismo sentido GUILARTE GUTIÉRREZ, Vicente. Insolvencia familiar y crisis matrimoniales. Endeudamiento del consumidor e insolvencia familiar. Editorial Aranzadi. España. 2009, 326. Con respecto al artículo 77.2 de la Ley Concursal, el autor afirma que "(... sin duda uno de los preceptos más complejos y de más difícil aplicación resultó ser el art. 77.2 donde, un tanto parcialmente, se disciplinaba el problema de la inclusión en la masa activa del concurso de los bienes matrimoniales comunes pues tan solo, lógicamente, babian de estar los pertenecientes al cónyuge concursado para lo cual resultaba necesario la previa disolución y liquidación de la sociedad de gananciales en sede concursal. Y ello por mor de la comunidad consorcial (...) como una comunidad germánica que obliga a liquidar todas las relaciones conyugales para finalmente determinar cual sea el activo perteneciente al cónyuge concursado único a integrar en la masa activa". 
monio. Es por ello que no resulta coherente con la finalidad ${ }^{56}$ del proceso que el cónyuge del deudor se beneficie de la última etapa concursal, sin haberse enfrentado a un proceso y sin haber puesto a disposición de los acreedores su patrimonio para el efectivo cumplimiento de las obligaciones.

Analizada la situación general, se concluye que, al extender los efectos de la exoneración del pasivo insoluto al cónyuge del deudor, estamos privando a los acreedores de hacer efectivo el cumplimiento de sus acreencias, pues éstos pierden, además de la garantía del patrimonio del deudor, la prenda del patrimonio del cónyuge, lo cual resulta injustificado a la luz tanto del derecho concursal como del derecho de las obligaciones.

\subsection{Carácter provisional}

La ley objeto de estudio, si bien incluye el mecanismo de la segunda oportunidad, tan anhelado por los deudores en situación de insolvencia, autoriza a los acreedores para solicitar su revocación, así "Cualquier acreedor concursal estará legitimado para solicitar del juez del concurso la revocación del beneficio de exoneración del pasivo insatisfecho cuando el deudor, durante los cinco años siguientes a su concesión: a) Incurriese en alguna de las circunstancias que conforme a lo establecido en el apartado 3 bubiera impedido la concesión del beneficio de la exoneración del pasivo insatisfecho. b) En su caso, incumpliese la obligación de pago de las deudas no exoneradas conforme a lo dispuesto en el plan de pagos. c) Mejorase sustancialmente la situación económica del deudor de manera que pudiera pagar todas las deudas pendientes sin detrimento de sus obligaciones de alimentos, o d) Se constatase la existencia de ingresos, bienes o derechos ocultados".

Respecto a las anteriores causales, cabe resaltar que los literales a), b) y d) reflejan un marcado interés del legislador en que el comportamiento del deudor beneficiario de la exoneración haya sido, de principio a fin, de buena fe; que su actuar haya sido transparente (deber de información), diligente y cumplidor de los deberes provenientes del acuerdo de pagos con sus acreedores ${ }^{57}$. Es por

56 JARAMILLO SIERRA, Camila. El mecanismo liberatorio del descargue de deudas en el régimen de insolvencia de persona natural a la luz del derecho comparado. Tesis de grado. Universidad Externado de Colombia, 2013, 126. Tal y como sucede en el caso colombiano, "En la presente Ley el deudor sobreendeudado no está facultado para solicitar directamente la liquidación de su patrimonio sino que por el contrario debe obligatoriamente baber intentado el mecanismo recuperatorio ya que la finalidad legislativa del concurso es ante todo el cumplimiento por parte del dendor de la mayor cantidad de obligaciones adquiridas y en su defecto el logro de acuerdos y negociaciones por medio del estímulo con los acreedores. La presente ley de insolvencia no busca acolitar al deudor en su fracaso, en su crisis económica, busca acompañarlo de una manera paternalista en el recorrido que lo llevará a superar esta desafortunada situación y que lo reincorporará en el mercado económico y le ayudará a recuperar la confianza del mercado $y$ de sus acreedores".

57 La norma no realiza una distinción entre si el plan de pagos fue incumplido de manera culpable o no por el deudor, lo que resulta un error, pues nuevamente estaríamos otorgándole un idéntico tratamiento a quien actúa de buena y mala fe. 
ello que, podría justificarse la revocación del mecanismo pues, como ha sido reiterado, la filosofía de perdón de deudas, está únicamente direccionada a beneficiar a quienes actúen en el marco de la bona fides.

Ahora bien, el literal c) constituye en nuestro parecer un infortunio del legislador, en el entendido que contraría la esencia y la finalidad de la segunda oportunidad.

Como hemos tenido la oportunidad de exponer, el mecanismo de la condonación de deudas, está orientado a otorgarle una segunda oportunidad al deudor que ha fracasado económicamente por causas ajenas a su voluntad, que no se encuentra en la posibilidad de cumplir con sus obligaciones y que, de no recibir una ayuda sufrirá una muerte económica y social. Lo anterior con el fin de que sus esfuerzos presentes alimenten un futuro prometedor y no resulten esclavos de obstáculos provenientes de deudas preexistentes. El perdón otorgado por la condonación resulta fructífero no solamente para la persona natural sino para la economía en general, toda vez que el deudor deja de acudir a la economía sumergida para ejercer sus actividades, y una vez exonerado de las obligaciones insolutas, recuperará su situación patrimonial e ingresará nuevamente al círculo económico del consumo.

Es por ello que, al incluir la norma la posibilidad de revocar la condonación de deudas, está truncando los fines del mecanismo pues, le ofrece al deudor la posibilidad de avanzar, de recuperarse patrimonialmente dejando a un lado las adversidades de la insolvencia y, posteriormente cuando le otorga dicho beneficio, crea la posibilidad de que sea revocado cuando el deudor "mejore sustancialmente su situación económica".

Lo anterior no ocurre en ninguna otra legislación y su inclusión en la normatividad resulta desconcertante, pues, de lograr una recuperación patrimonial, el deudor puede ser perseguido por los acreedores para la satisfacción de las obligaciones; en otros términos, el descargue será útil si y sólo si el deudor continúa en estado de pobreza. Tal situación trae como consecuencia el inevitable retorno a la economía sumergida, al testaferrato y al desincentivo para que los deudores retomen su actividad productiva.

Con relación a esta característica de la condonación de la ley española, cabe traer a colación un informe realizado por el Banco Mundial ${ }^{58}$ en el que acertadamente se afirma que los beneficios de la exoneración de deuda, pueden convertirse en meras ilusiones, si no se respeta la condonación una vez concluido el procedimiento.

Ahora bien, tras comprender de qué modo se incluyó la exoneración de deudas en la legislación concursal para la persona natural, podemos concluir que "la segunda oportunidad" del Real Decreto Ley, no satisface las necesidades económicas y sociales de los deudores y no es coherente con lo enunciado en 
la exposición de motivos, donde hace referencia a que el deudor gracias a la promulgación de esta normatividad, se liberará de "arrastrar indefinidamente una losa de deuda que nunca podrá satisfacer", expresión que se convierte en una mera ilusión.

\section{DIRECTRICES Y RECOMENDACIONES INTERNACIONALES}

Haciendo un breve recuento de los estudios económicos, financieros y jurídicos en torno a la insolvencia empresarial y de personas naturales, cabe resaltar la labor realizada por la CNUDMI en su "Guía legislativa sobre el régimen de insolvencia" en la que a grandes rasgos presenta varios esquemas concursales efectivos, con el fin de que cada país adopte el que se adhiere mejor a sus condiciones sociales, políticas, jurídicas y económicas.

El capítulo VI de la mencionada guía, aborda la exoneración del pasivo del deudor en el marco de un procedimiento de insolvencia y ofrece varias opciones de aplicación de dicho mecanismo, siempre con la finalidad de superar las dificultades económicas del deudor, sin dejar a un lado los intereses de orden público ni a los acreedores afectados por el concurso.

De este modo, la guía plantea dos caminos para afrontar la insolvencia, acorde con la política o trato que se dé a la persona insolvente. Si la finalidad es otorgarle al deudor los mecanismos suficientes para la superación de la insolvencia es decir, brindarle una segunda oportunidad para propiciar la actividad laboral y económica, la solución será el perdón o la condonación de las deudas que le estén impidiendo avanzar.

Si por el contrario, quien incumple sus obligaciones es considerado como un deshonesto $y$, por ende, se considera debe ser sancionado y castigado, el mecanismo aplicado se reducirá a una exoneración prolongada en el tiempo, con reducción de las deudas objeto de condonación, múltiples obstáculos de ingreso al proceso y de salida exitosa del mismo. En dado caso, resulta más apropiado "imponer restricciones y condiciones cuando el deudor no baya obrado con bonradez, no baya cooperado con el representante de la insolvencia o no baya cumplido sus obligaciones conforme al régimen o, en casos más extremos, cuando baya incurrido en una conducta delictiva" 59 .

Sin perjuicio de dicha distinción, la recomendación de la CNUDMI, respecto a la aplicación del mecanismo de la segunda oportunidad, se centra en "reducir al minimo las deudas excluidas con objeto de facilitar que el deudor pueda reemprender su negocio sobre una base firme, y enunciar claramente tales exclusiones en el régimen de la insolvencia" ${ }^{\prime \prime}$. Lo anterior encuentra fundamento en "la eficacia, celeridad y eficiencia que deben caracterizar al régimen de insolvencia pues, la existencia de figuras complejas,

60 Ibídem, p. 336 
afecta gravemente al proceso en la práctica, basta el punto de ser inútil para los sujetos de este concurso" ${ }^{\prime \prime}$.

Ahora bien, con respecto a las recomendaciones realizadas por el Fondo Monetario Internacional, resulta necesario destacar que, al igual que las sugerencias de la CNUDMI, las mismas no fueron acatadas.

En el capítulo de instrumentos para afrontar la deuda, el informe describe cómo el régimen de insolvencia en España, y en especial para la persona natural, se encuentra subutilizado en comparación con otros países, estableciendo como causas principales su severidad con el deudor, que al no existir la figura del descargue de deudas o exoneración del pasivo, la responsabilidad es ilimitada, lo que considera en extremo ineficiente pues, aún países de tradiciones jurídicas diferentes (como Francia e Inglaterra) utilizan mecanismo de flexibilización de las deudas. Así mismo, considera que otro de los problemas que buscó solucionarse con la ley de emprendedores, fue la aplicación de la segunda oportunidad, sin embargo, la clasifica como una medida fracasada toda vez que excluyó de la exoneración a los acreedores privilegiados, lo que implica que la mayoría de deudores no se podrá condicionar a la exoneración.

Tras mencionar estos errores de la legislación de insolvencia para la persona natural, concluye recomendando una modificación al régimen concursal, donde el deudor cuente con un esquema acorde a su situación económica y jurídica, independiente de la persona jurídica y el empresario, donde se incluya además, el descargue de deudas. Lo anterior insistiendo en que el mencionado mecanismo no pondrá en peligro la cultura de pago es decir el cumplimiento de las obligaciones por parte de los deudores insolventes ${ }^{62}$.

Resulta claro que el legislador español ha hecho caso omiso de las recomendaciones realizadas por la CNUDMI, INSOL International ${ }^{63}$ y, el Fondo Monetario Internacional, al igual que de la experiencia de países vecinos como Francia, Alemania, Inglaterra e Italia, entre otros.

La reticencia del legislador a aceptar las recomendaciones mencionadas, podría ser causada por el temor a que los deudores de mala fe abusen del mecanismo de la condonación y vean exoneradas sus deudas, creando de este modo una cadena de incumplimientos que llevarían a un serio problema económico y a una marcada cultura del no pago. Lo anterior no resulta justificado si el régimen de insolvencia incluye, como fue dicho con antelación, drásticos filtros para ser aceptado al mismo, dentro de los que se halla, sin lugar a dudas, la calificación del sobreendeudamiento del deudor.

61 Ob. Cit. JARAMILLO SIERRA, p. 47.

62 FONDO MONETARIO INTERNACIONAL. Selected Issues, Spain. IMF Country Report No. 14/193, julio 2014, 22, 23, 24.

63 INSOL INTERNATIONAL (International Federation of Insolvency Professionals), Consumer Debt Report-Report of Findings and Recommendations, May 2001. El presente documento puede consultarse en: www.insol.org/pdf/consdebt.pdf (15.03.2010). 
Además de lo anterior, es menester resaltar que, otro impedimento del legislador español para alcanzar la exoneración, es la marcada favorabilidad del régimen de insolvencia al acreedor, lo cual, además de verse reflejado en la normatividad civil (artículos 1911,1919,1920) derogada, pero igualmente adoptada en la actual ley concursal, fue públicamente conocido en la exposición de motivos de la ley, objeto de estudio, al afirmar que, un régimen de insolvencia debe proteger al deudor pero "(...) sin minar [a] los acreedores, pues en tal caso se produciría precisamente el efecto contrario al pretendido: el retraimiento del crédito o, al menos, su encarecimiento" asimismo se afirmó, refiriéndose a la revocatoria de segunda oportunidad de los acreedores, que "[se] permitirá revocar dicho beneficio por las razones de justicia bacia los acreedores (... $)^{\prime \prime 64}$.

\section{CONCLUSIONES}

A pesar de las recomendaciones emitidas por órganos internacionales, las intervenciones doctrinales y las peticiones ciudadanas abogando por un régimen de insolvencia adecuado para superar la crisis del deudor, es claro que el legislador español se negó a estructurar un adecuado esquema de insolvencia que permitiera al deudor beneficiarse de una segunda oportunidad. Lo anterior, toda vez que en la exposición de motivos de la ley se hace evidente que las fuentes a las cuales acudió el legislador fueron las siete partidas y el derogado artículo 1920 del Código Civil, dejando a un lado los estudios económicos, políticos y sociales que le fueron presentados al gobierno con el fin de que fuera creada una adecuada ley de sobreendeudamiento.

Dicha negativa resulta contradictoria en la medida en que, encontrándose España en situación de recesión económica, requiere agilizar los trámites de creación de empresa, de fomento a la inversión y de generación de capital, más no de apoyo a la economía sumergida, al desempleo y a la inactividad económica.

Como lo afirma RODRÍGUEZ ESPITIA ${ }^{65}$, "Un régimen de insolvencia persigue, de manera equilibrada, el logro de unos objetivos fundamentales, los cuales en ocasiones pueden diferir de otras disposiciones legales como el tratamiento a los derechos de los acreedores garantizados, los derechos de los trabajadores, los órdenes de prelación legal, entre otras y que son expresiones de la especialidad. Todas estas diferencias se justifican en la medida en que se está ante una materia especial que requiere el cumplimiento de unos objetivos que ban sido identificados en la Guía Legislativa de la CNUDMI igualmente especiales (... )", es por ello que, no resulta lógico que ante una situación de desequilibrio económico, el

64 Ob. Cit. Real Decreto Ley 01/2015. Exposición de motivos.

65 RODRIGUEZ ESPITIA, Juan José. Nuevo Régimen de Insolvencia. Universidad Externado de Colombia, Bogotá, 2007, 31. 
legislador español impida al deudor, por su sesgada filosofía pro creditoris, salir de la crisis a través de la exoneración de pasivos.

A modo de conclusión, podemos afirmar que la condonación de deudas propuesta en el Real Decreto Ley 01/2015 resulta ineficiente, inapropiada, inane e inocua, pues, como fue analizado, una segunda oportunidad en la que a) no se analizan las causas que originaron la insolvencia ${ }_{i}$ b) las deudas exonerables, siendo mínimas, no guardan relación con las necesidades reales de la persona natural, y c) los acreedores tienen la potestad de revocar y por ende truncar la "segunda oportunidad" brindada al deudor, una vez el mismo logre recuperarse económicamente, resulta un sinsentido jurídico.

El legislador español, con el fin de dar un adecuado giro a la insolvencia de la persona natural, debe, ante todo, concientizarse de que existen deudores honestos que por causas extrañas a su voluntad, lo han perdido todo.

\section{BIBLIOGRAFÍA}

Alfonso X. Las Siete Partidas. Quinta Partida, Título XV, Ley III.

ARIAS, Javier. Ley de Insolvencia: Insolvenzordnung (InsO). Revista de Derecho Privado, № 1, Universidad Externado de Colombia, Bogotá, enero- junio de 1997.

BANKRUPTCY LAW AND ENTREPRENEURSHIP, Law Working Paper Nº 105/2008, febrero 2008.

BANCO MUNDIAL, Informe sobre el tratamiento de la persona física. Ver: http:// siteresources.worldbank.org/INTGILD/Resources/WBInsolvencyOfNaturalPersonsReport_01_11_13.pdf

BLUM, A. Brian. Bankruptcy and debtor/ creditor, $5^{\mathrm{a}}$ Ed., Estados Unidos, Aspen Publishers, 2010.

CNUDMI, Guía legislativa sobre el régimen de la Insolvencia, New York, 2006.

COMISIÓN EUROPEA. Diario Oficial de la Unión Europea, L. 74/65. Recomendación de la Comisión de 12 de marzo de 2014 "Sobre un nuevo enfoque frente a la insolvencia y el fracaso empresarial".

Common operational european definition of overindebtedness. Informe en el que se busca unificar el concepto de sobreendeudamiento y el modo a través del cual se abordará de manera homogénea la insolvencia. Contract n VC/2006/0308, de 19.12.2006.

CUENA CASAS, Matilde. El concurso de acreedores de persona casada en régimen de gananciales. Endeudamiento del consumidor e insolvencia familiar, Editorial Aranzadi, España, 2009. 
CUENA CASAS, Matilde. Fresh Start y mercado crediticio. Indret 3/2011. Universidad complutense de Madrid, Barcelona, 2011.

CUENA CASAS, Matilde. Insolvencia de la persona física y sobreendeudamiento hipotecario. Revista derecho concursal y paraconcursal, Núm. 17, Sección Varia, Editorial La Ley, 2012.

CUENA CASAS, Matilde. ¿Un régimen de segunda oportunidad? Opinión, Revista 60, 30 marzo 2015.

DASSO, Ariel. La exaltación del consumo y el derecho del consumidor al procedimiento concursal. "Composizione delle crisi da sovraindebitamento", Convegno internazionale, Roma, 7-8 giugno 2012

FONDO MONETARIO INTERNACIONAL. Selected Issues, Spain. IMF Country Report No. 14/193, julio 2014, 22, 23, 24. Ver: http://ep00.epimg.net/descargab les/2014/07/10/2509f16067f17898af32a70b8958b979.pdf

GALGANO, Francesco. Storia del diritto commerciale. Il Mulino, 1980.

GUILARTE GUTIÉRREZ, Vicente. Insolvencia familiar y crisis matrimoniales. Endeudamiento del consumidor e insolvencia familiar. Editorial Aranzadi. España. 2009.

GURREA CHALÉ, Aurelio. Los créditos contra la masa. La problemática de su pago en el derecho concursal español. En Libro homenaje al profesor Emilio Beltrán, $9^{\circ}$ Congreso Iberoamericano de Derecho Concursal, Instituto Iberoamericano de Derecho Concursal, 2014.

HINESTROSA, Fernando. Tratado de las Obligaciones. Concepto, Estructura, Vicisitudes. Universidad Externado de Colombia, 3ra Ed., Bogotá, 2007

INSOL INTERNATIONAL. Consumer debt report. Report of findings and recommendations, London, 2001.

JARAMILLO SIERRA, Camila. El mecanismo liberatorio del descargue de deudas en el régimen de insolvencia de persona natural a la luz del derecho comparado. Tesis de grado. Universidad Externado de Colombia, 2013.

MAIRATA LAVIÑA, Jaime. Novedades tributarias en materia concursal introducidas por el RDL 1/2015: más de lo mismo. ¿Hay derecho?, 5 abril de 2015.

MILLER, Alejandro. Reflexiones sobre la calificación del concurso y los administradores sociales. En Libro homenaje al profesor Emilio Beltrán, $9^{\circ}$ Congreso Iberoamericano de Derecho Concursal, Instituto Iberoamericano de Derecho Concursal, 2014. 
PULGAR EZQUERRA, Juana. El concurso de acreedores. La declaración. La ley, Madrid, 2009.

PULGAR EZQUERRA, Juana. Concurso y Consumidores en el marco del Estado Social de Bienestar, en Revista de Derecho Concursal y Paraconcursal, N॰ 9, Sección Estudios, La Ley, España, segundo semestre de 2007.

PULGAR EZQUERRA, Juana. El presupuesto objetivo de la prevención y tratamiento de las crisis económicas de los consumidores. Endeudamiento del consumidor e insolvencia familiar, Editorial Aranzadi, España, 2009.

RODRIGUEZ ESPITIA, Juan José. Nuevo Régimen de Insolvencia. Universidad Externado de Colombia, Bogotá, 2007.

SCHMIDT, Karsten. El derecho alemán. Una comedia de equivocaciones. Endeudamiento del consumidor e insolvencia familiar, Editorial Aranzadi, España, 2009.

SENENT, Santiago. Discharge y sobreendeudamiento de particulares en el ámbito del derecho norteamericano y español. Documento de Trabajo del Departamento de Derecho Mercantil, número 2012/47, Universidad Complutense de Madrid, 2012.

SOTOMONTE MUJICA, David Ricardo. Insolvencia transfronteriza: evolución y estado de la materia. Universidad Externado de Colombia, 2009.

RAGA, José T. Análisis económico de la insolvencia familiar. Endeudamiento del consumidor e insolvencia familiar, Editorial Aranzadi, España, 2009

\section{NORMATIVIDAD COMPARADA}

Código Civil español.

Ley 14 de 2013, de 27 de septiembre. BOE núm. 233 del 28 de septiembre de 2013.

Real Decreto Ley 01/2015, de 27 de febrero. BOE núm. 51 del 28 de febrero de 2015.

Williams v. Estados Unidos Fidelity \& Garantía Co., 236 EE.UU. 549, 236 EE.UU. $554-555$.

United States Code, Bankruptcy Code.

Code de la Consommation.

Código da Insolvência e da recuperação de empresas.

Código General del Proceso. 